\title{
Polymerase Chain Reaction: An Innovative Tool in Periodontal Diagnosis
}

\author{
Suvarna H Patil, Kishore G Bhat, Paresh S Lotlekar, Laxmi V Hombal
}

\begin{abstract}
Bacterial species colonizing the surfaces of the human oral cavity play an important role in oral health and disease and thus an accurate means of identification is crucial. Traditionally, identification has been based on microscopy, biochemical tests, immunofluorescence staining and antibiotic sensitivity. However, these tests are labor-intensive and costly, providing sometimes inconsistent results that make identification rather tentative. Recently, molecular DNA-based techniques have been used to identify bacteria directly from clinical samples. Development of a microbiological diagnostic kit using this technology therefore requires the ability to extract the bacterial DNA from the plaque sample and amplify the specific DNA sequence of the target periodontal pathogen. Polymerase chain reaction has emerged as the most powerful tool for the amplification of the genes and their RNA transcripts. The focus of this review is to describe the current status of the DNA-based method PCR which has become a standard diagnostic and research tool in dentistry.
\end{abstract}

Keywords: Periodontal disease, DNA-based techniques, Polymerase chain reaction, Diagnostic tool.

How to cite this article: Patil SH, Bhat KG, Lotlekar PS, Hombal LV. Polymerase Chain Reaction: An Innovative Tool in Periodontal Diagnosis. World J Dent 2013;4(1):60-66.

\section{Source of support: Nil}

Conflict of interest: None declared

\section{INTRODUCTION}

Periodontal diseases are chronic mixed anaerobic infections with a remarkably high prevalence and morbidity. Whereas gingivitis, with some exceptions, is a reversible polymicrobial infection with no single associated bacterial agent, periodontitis is moderately to rapidly progressive and is associated with facultative or obligate anaerobic pathogens. The species Aggregatibacter actinomycetemcomitans, Tannerella forsythia, Campylobacter rectus, Eikenella corrodens, Fusobacterium nucleatum, Porphyromonas gingivalis, Prevotella intermedia and several forms of uncultivable spirochetes play major roles in the pathogenesis. $^{1-3}$

For diagnosis of the activity of the different forms of periodontitis, clinical symptoms alone may not be sufficient, because they provide a historical record only (pocket formation, attachment loss and alveolar bone loss) or have low predictive value (bleeding on probing). But predictions of recurrence of disease and prognosis for the patient can be significantly improved when the presence or absence of periodontal pathogens is monitored as well. ${ }^{3}$
Historically, culture methods have been widely used in studies aimed at characterizing the composition of the subgingival microflora and are still considered the reference method (gold standard) when determining the performance of new microbial diagnostic methods. However, culture techniques have important shortcomings. Culture methods can only grow live bacteria; therefore strict sampling and transport conditions are essential. Moreover, some of the putative pathogens, such as Treponema species and T. forsythia are fastidious and difficult to culture. Periodontopathogenic bacteria are mainly Gram-negative requiring anaerobic growth conditions. Therefore, for diagnostic procedures problems of sampling, transport and cultivation have to be taken into consideration. The sensitivity of culture methods is rather low, since the detection limits for selective and nonselective media average $10^{3}$ to $10^{4}$ bacteria and hence low numbers of a specific pathogen in a pocket are undetected. However, the most important drawback is that culture requires sophisticated equipment and experienced personnel and is relatively time consuming and expensive. When using this method, clinicians must be confident that the laboratory has the appropriate technology and expertize in periodontal microbiology to communicate diagnostically and therapeutically useful information to them.

The development of techniques in molecular biology aimed at the detection of bacterial pathogens has not only allowed the acquisition of knowledge in microbial genetics, but also has set the basis for the development of improved diagnostic techniques. ${ }^{4-6}$ The principles of molecular biology techniques reside in the analysis of deoxyribonucleic acid (DNA), ribonucleic acid (RNA) and the structure or function of protein. ${ }^{7,8}$ Diagnostic assays employing molecular biology techniques require specific DNA fragments that recognize complementary-specific bacterial DNA sequences from target microorganism. Development of a microbiological diagnostic kit using this technology therefore requires the ability to extract the bacterial DNA from the plaque sample and amplify the specific DNA sequence of the target periodontal pathogen.

Polymerase chain reaction (PCR) has emerged as the most powerful tool for the amplification of the genes and their RNA transcripts. This technique, developed in 1985, is the single technique used almost universally to study DNA 
and RNA obtained from a variety of tissue sources. PCR allows large quantities of DNA to be obtained in a simplified and automated manner. ${ }^{7,9,10}$ Dr Kary Banks Mullis was awarded the Nobel Prize in chemistry in 1993 for his discovery of PCR.

PCR is an excellent tool for directly identifying periodontal pathogens in subgingival samples. Due to its sensitivity and specificity, it is a rapid and efficient method for detecting, identifying and differentiating organisms. ${ }^{11}$ PCR is considered the easiest and fastest method in clinical samples. ${ }^{12}$ PCR may soon become the ideal detection method for periodontal pathogens due to its greater ease of use in comparison to cultures associated with biochemical identification tests. It also demonstrates excellent detection limits with few cross-reactions under ideal conditions. ${ }^{13}$

\section{PCR Technology}

PCR typically begins with the isolation of DNA from a fresh tissue specimen. By heating the complementary double strands, DNA splits into single stranded forms intended to act as the template dictating the nucleotide sequence in vitro. The amplification is followed using a DNA polymerase that requires a primer, or known short oligonucleotide sequence corresponding to the border of the region that is amplified. For obtaining amplified fragments of constant length and in large quantities, a second primer, complementary of the opposed chain, must be used to anneal (bind) the template and flank the region of interest. This amplification can be performed several times (usually 25-40), known as cycles. In each cycle the process of complementary chain denaturation, primer hybridization, and primer extension by means of the polymerase takes place. With each cycle there is an exponential increase in the quantity of DNA. Throughout this process the temperature during the cycle is critical to control the double chain denaturation and the stability of the hybridization between the model fragment and the primer. In 1988 a thermostable DNA polymerase isolated from the organism Thermus aquaticus, known as Taq-DNA polymerase, was developed. ${ }^{6}$ This Taq-DNA polymerase has allowed automatization of the reaction using specific appliances called thermocyclers (Fig. 1).

A typical thermal cycle might be as follows:

1. Heat denaturation at $94^{\circ} \mathrm{C}$ for 20 seconds

2. Primer annealing at $55^{\circ} \mathrm{C}$ for 20 seconds

3. Primer extension at $72^{\circ} \mathrm{C}$ for 30 seconds.

\section{Post Amplification Detection}

Following PCR, the amplification product can be detected using gel electrophoresis (Fig. 2) followed by ethidium bromide staining and visualization with ultraviolet

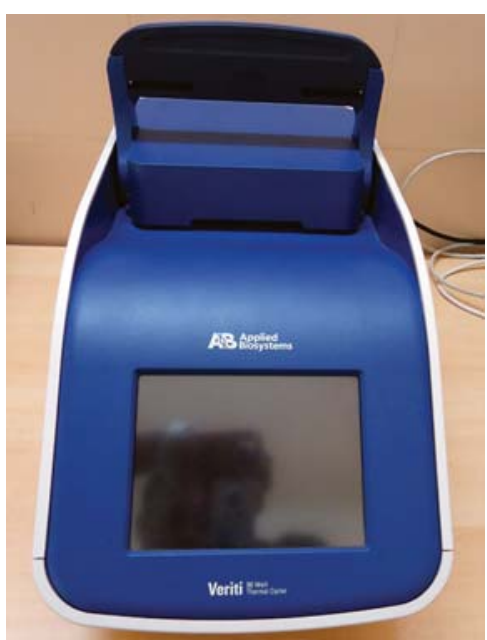

Fig. 1: Thermocycler

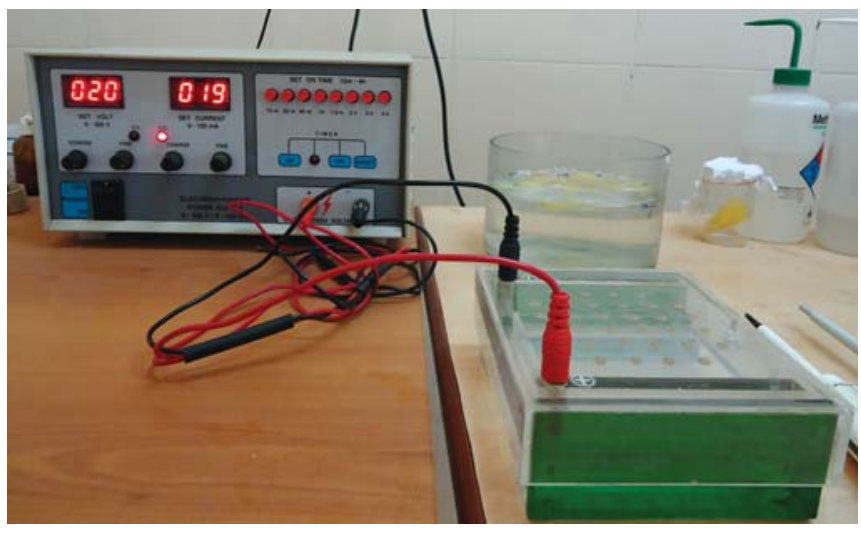

Fig. 2: Gel electrophoresis

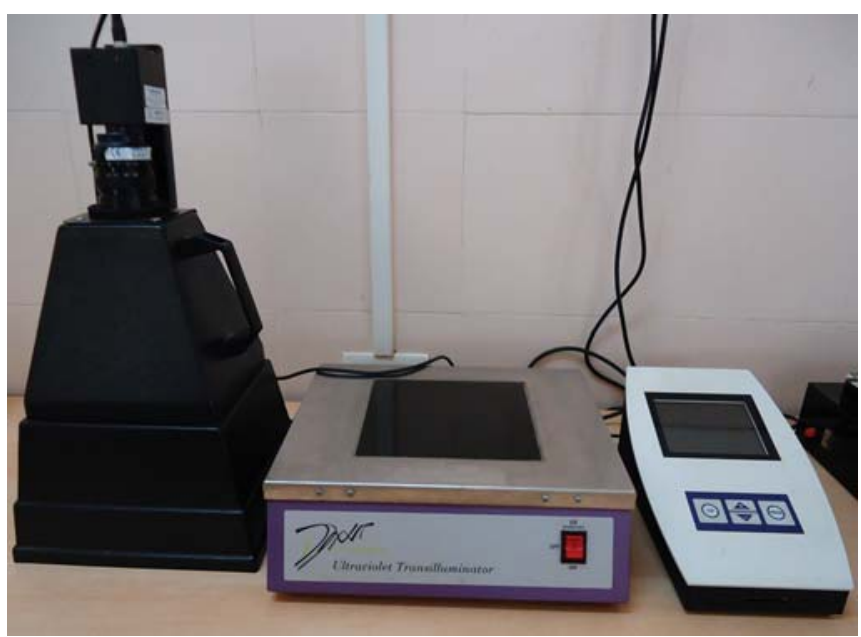

Fig. 3: Ultraviolet transilluminator

transillumination (Fig. 3). Visualization of a band (Fig. 4) containing DNA fragments of a particular size can indicate the presence of the target sequence in the original DNA sample. Absence of a band may indicate that the target sequence was not present in the original DNA sample. Confirmation of the amplicons can be made by Southern blotting using specific probes. 


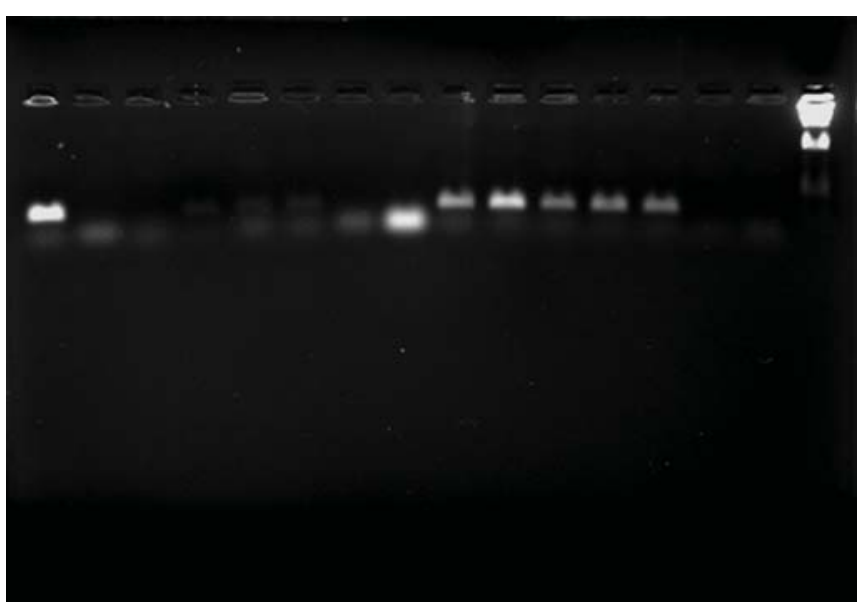

Fig. 4: Ethidium bromide-stained PCR products

\section{Variations of PCR}

Various researchers have used the flexibility of PCR with great efficiency to come out with several variations to suit their needs and the laboratory facilities. These variations are: Real-time PCR, nested PCR, multiplex PCR, reverse transcription PCR, touchdown PCR, arbitrarily primed PCR, inverse PCR, allele-specific PCR, asymmetric PCR, hot start PCR, core sample PCR, degenerate PCR, PCR-ELISA, methylation-specific PCR, quantitative PCR, assembly PCR or polymerase cycling assembly, helicase-dependent amplification PCR, intersequence-specific PCR, ligationmediated PCR, miniprimer PCR, solid phase PCR, touchdown PCR, colony PCR, overlap extension PCR, thermal asymmetric interlaced PCR, universal fast walking, variable number of tandem repeats, long PCR, multiplex ligation-dependent probe amplification, digital PCR.

\section{APPLICATIONS IN DENTISTRY}

1. Detection of periodontal pathogens

2. Detection of cariogenic pathogens

3. Detection of microorganisms involved with endodontic infections

4. Detecting viruses present in host cells: To detect human papillomavirus and hepatitis $\mathrm{C}$ virus, and also in other studies that suggest virus involvement in the etiology of periodontal disease.

5. Detection of useful markers in diagnostic and prognostic of some types of oral cancer

6. Quantitative estimation of different microorganisms.

\section{APPLICATIONS IN PERIODONTICS}

\section{Detection of Bacteria}

Many studies have utilized PCR-based methods to detect specific species directly from oral clinical samples. These studies focused on the detection of few putative pathogenic species typically associated with periodontal disease, such as Porphyromonas gingivalis, Tannerella forsythia, Treponema denticola and Aggregatibacter actinomycetemcomitans. ${ }^{14-17}$

\section{Porphyromonas Gingivalis}

Shelburne et al, ${ }^{18}$ in 2002, in order to explore expression of Porphyromonas gingivalis virulence factors in periodontitis subjects, modified methods for quantitative measurement of gene activation. They found quantitative (real-time) reverse transcription PCR (qRT-PCR) well suited to examine gene expression of the oral anaerobe P. gingivalis in periodontal disease in vivo, and they also described their first results with qRT-PCR using a selection of putative virulence factors. The efficacy of PCR method for detection of $P$. gingivalis from salivary samples was compared with that of bacterial culture by Mättö et al, ${ }^{19}$ in 1998. The authors showed that this bacterium was detected in saliva three times more often by PCR than by culture.

\section{Treponema Socranskii}

PCR technique was also used by Sakamoto et al, ${ }^{20}$ in 1999, for the detection and identification of Treponema socranskii associated with periodontal disease. Pathogen frequency correlated with increasing gingival index scores in both children and adults. T. socranskii was detected more often in subgingival plaque samples than in saliva samples.

\section{Aggregatibacter Actinomycetemcomitans}

Studies have detected Aggregatibacter actinomycetemcomitans using PCR in the most distinct patterns in a population with (70\%) and without (19\%) periodontal disease. These studies have also shown the sensitivity and specificity of PCR in comparison to traditional culture methods. ${ }^{21,22}$ Okada, Hayashi, Nagasaka, ${ }^{23}$ in 2000, aimed to detect the presence of Aggregatibacter actinomycetemcomitans and $P$. gingivalis in plaque samples from children, collected from their toothbrushes using PCR. This survey indicated that A. actinomycetemcomitans and P. gingivalis are rarely present in oral cavities of healthy children.

\section{Other Bacterias of Periodontal Importance}

\section{Capnocytophaga Sputigena, \\ C. ochracea and C. gingivalis}

Hayashi et al, ${ }^{24}$ in 2001, accomplished a study whose purpose was to detect the presence of Capnocytophaga 
sputigena, C. ochracea and C. gingivalis, using PCR, in plaque samples taken with a toothbrush from children. This survey indicated that $C$. sputigena had a moderate prevalence, whereas $C$. ochracea and $C$. gingivalis were commonly detected in the oral cavities of children, suggesting that these three species become established in the early years.

Prevotella intermedia, Prevotella nigrescens, Bacteroides forsythus, Treponema denticola and Campylobacter rectus: Using the same methodology, Okada, Hayashi, Nagasaka, ${ }^{25}$ in 2001, assessed the presence of Prevotella intermedia, Prevotella nigrescens, Bacteroides forsythus, Treponema denticola and Campylobacter rectus. The study indicated that $P$. intermedia and $T$. denticola were more associated with periodontal disease, $B$. forsythus and $P$. nigrescens had a moderate prevalence in all clinical groups, while $C$. rectus were the most commonly detected species in the oral cavities of children also suggesting establishment in their early years.

T. socranskii, T. denticola and P. gingivalis: Other bacteria studied by Takeuchi, et al, ${ }^{26}$ in 2001, were T. socranskii, T. denticola and P. gingivalis. They aimed to identify these microorganisms by PCR, and to clarify the relationship between their presence and the severity of clinical periodontal parameters such as bleeding on probing, probing depth and gingival index. So, T. socranskii, T. denticola and $P$. gingivalis were identified by PCR in plaque and saliva samples, and it was found that the presence of T. socranskii was associated with periodontitis. T. socranskii was more frequently detected in plaque samples from aggressive or chronic periodontitis patients than from healthy subjects. The detection frequency of $T$. socranskii was elevated at sites where severe periodontal tissue destruction was observed. The prevalence of these three microorganisms was correlated with various clinical parameters. The data suggested that their presence was associated with the severity of periodontal tissue destruction.

In 2002, Kimura et $\mathrm{al}^{27}$ carried out a cross-sectional study to assess the prevalence and distribution of putative bacteria in 144 children (2 to 13 years old, 12 subjects from each year of age) who showed no or negligible periodontal inflammation. This study used a PCR assay with speciesspecific primer for 10 putative periodontopathogenic bacteria: $P$. gingivalis, $B$. forsythus, $P$. intermedia, $P$. nigrescens, C. rectus, E. corrodens, A. actinomycetemcomitans, C. ochracea, C. sputigena and T. denticola. A subject-based analysis of bacterial infection indicated that the number of bacterial species in plaque samples had increased gradually by age in this study, and further suggested that E. corrodens, A. actinomycetemcomitans, C. ochracea, C. sputigena and C. rectus could be early colonizers of dental plaque. Moreover, no positive association for bacterial combinations in colonization was found in this study of periodontally healthy children.

$P$. gingivalis, $P$. intermedia and A. actinomycetemcomitans: Doungudomdacha, Rawlinson, Douglas, ${ }^{11}$ in 2000, developed a sensitive quantitative-competitive PCR (QCPCR) technique for the identification of $P$. gingivalis, $P$. intermedia and A. actinomycetemcomitans, in either laboratory strains or subgingival plaque samples, with specific primers for the fimA gene, the 16S rRNA gene and the $l k t A$ gene, respectively. This method proved to be rapid, reproducible and extremely sensitive; the primers employed were highly specific and capable of differentiating the target organisms from a number of closely related cultivable species.

Real-time PCR offers a sensitive, efficient and reliable approach to quantitation. Using the TaqMan system, Lyons, Griffen, Leys, ${ }^{28}$ in 2000, were able to determine both the amount of $P$. gingivalis and the total number of bacteria present in plaque samples directly without culturing. In addition, it allowed them to determine the percentage of $P$. gingivalis in a complex sample.

Sakamoto et al, ${ }^{29}$ in 2001, compared conventional PCR method, real-time PCR method using the LightCycler ${ }^{\mathrm{TM}}$ system, and the culture method to detect and quantify periodontopathogenic bacteria including A. actinomycetemcomitans, B. forsythus, $P$. gingivalis, $T$. denticola and $T$. socranskii in saliva and subgingival plaque. There was good agreement between the results of conventional PCR and real-time PCR methods for all saliva samples. Use of the LightCycler ${ }^{\mathrm{TM}}$ system greatly simplified the process, and was able to determine the amount of periodontopathogenic bacteria within an hour. Periodontopathogenic bacteria were more frequently detected in saliva than in subgingival plaque samples. This study suggested that saliva is equal to or better than subgingival plaque for detecting and quantifying periodontopathogenic bacteria in the oral cavity.

T. denticola, Eubacterium saphenum, Porphyromonas endodontalis, P. gingivalis, T. forsythensis, Filifactor alocis, Prevotella denticola, Cryptobacterium curtum, Treponema medium, T. socranskii, and Actinomyces naeslundii: Kumar et al, ${ }^{30}$ in 2003, evaluated the association of newly identified bacterial species or phylotypes with periodontitis. Targets for investigation included both uncultivated phylotypes and characterized species that were not previously thought to be associated with periodontitis. In addition, species previously strongly linked to periodontitis were included for comparison. Species-specific ribosomal 16S primers for PCR amplification were developed for detection of new species. Associations with chronic periodontitis were 
observed for several new species or phylotypes. Species more commonly found in subjects with chronic periodontitis than in healthy subjects included T. denticola, Eubacterium saphenum, Porphyromonas endodontalis, P. gingivalis, T. forsythensis, Filifactor alocis, Prevotella denticola, Cryptobacterium curtum, Treponema medium, T. socranskii and Actinomyces naeslundii.

The MicroDent Test (Hain Diagnostika Ltd., Nehren, Germany) is a commercially available method using multiplex PCR that tests for five oral species and has been used to compare the microbial profiles of subgingival plaque samples in oral health and periodontitis. ${ }^{31,32}$

MyPerioPath from OralDNA labs (Brentwood, TN) is a commercially available service that utilizes TaqMan PCR to determine the presence and the microbial profile of 13 putative pathogens from oral specimens provided by clinicians. ${ }^{33}$

\section{Detection of Viruses}

To begin to elucidate on a possible involvement of human viruses in periodontal disease, Parra and Slots, ${ }^{34}$ in 1996, determined the prevalence of human cytomegalovirus (HCMV), Epstein-Barr virus type 1 and 2 (EBV-1 and -2), herpes simplex virus, human papillomavirus and HIV in crevicular fluid from individuals with various forms of periodontal disease. Viral identification was performed using a PCR-based technique. This study provided evidence of human viruses in the crevicular fluid of many advanced adult periodontitis lesions.

\section{Studying Chemokines}

In order to study the role of chemokines in periodontal diseases, Garlet et al, ${ }^{35}$ in 2003, examined the expression of chemokines, chemokine receptors and cytokines characteristic of the patterns of immune response in gingival biopsies from aggressive periodontitis and chronic periodontitis patients by means of reverse transcription-PCR (RT-PCR) techniques. The expression of the chemokines macrophage inflammatory protein-1 alpha and interferongamma inducible protein 10 and of their respective receptors, CCR5 and CXCR3, were more prevalent and higher in aggressive periodontitis. In addition, these patients also showed higher interferon-gamma expression and lower interleukin (IL)-10 expression. In contrast, chronic periodontitis patients exhibited a more frequent and higher expression of monocyte chemoattractant protein-1 and its receptor CCR4, and higher expression of IL-10.

\section{Limitations of PCR}

While a very powerful technique, PCR can also be very tricky. The polymerase reaction is very sensitive to the levels of divalent cations (especially $\mathrm{Mg}^{2+}$ ) and nucleotides, and the conditions for each particular application must be worked out. Primer design is extremely important for effective amplification. The primers for the reaction must be very specific for the template to be amplified. Cross reactivity with nontarget DNA sequences results in nonspecific amplification of DNA. Also, the primers must not be capable of annealing to themselves or each other, as this will result in the very efficient amplification of short nonsense DNAs.

The reaction is limited in the size of the DNAs to be amplified (i.e. the distance apart that the primers can be placed). The most efficient amplification is in the 300-1,000 bp range. However, amplification of products up to $4 \mathrm{~Kb}$ has been reported. Also, Taq polymerase has been reported to make frequent mismatch mistakes when incorporating new bases into a strand. The most important consideration in PCR is contamination. If the sample that is being tested has even the smallest contamination with DNA from the target, the reaction could amplify this DNA and report a falsely positive identification. ${ }^{36}$

\section{Future of PCR}

PCR is the wave tool of the future in molecular biology. PCR technology not only overcomes the time-consuming process using conventional culture and microscopic analysis, but also has increased sensitivity, specificity. An interesting PCR is digital PCR. Digital PCR combines the amplification and quantification power of PCR with limiting dilution of template targets. This allows not only for the quantification of PCR products but also for quantification of rare nucleic acid targets. In the future, incorporation of computer in different PCR will help in deciphering the entire genome of various organisms and generate more information on the evolutionary relation between organisms. ${ }^{36}$

\section{CONCLUSION}

The recognition of the universality of the genetic code in living organisms has been essential to the development and application of genetic technologies. The publication of the PCR technique was a revolutionary watershed for medicine and science. It has become a standard diagnostic and research tool in dentistry, permitting the early diagnosis diseases. ${ }^{37}$ This approach not only enables the diagnosis of putative pathogens but also contributes to the identification of new ones. ${ }^{38}$ Microbiological testing that uses DNA probes and primers in advanced forms of periodontitis is a very promising tool to determine active disease and predict future attachment loss, ultimately improving treatment prognosis. Therefore, PCR has revolutionized the understanding of periodontal pathogenesis. ${ }^{20}$ 


\section{REFERENCES}

1. Slots J, Rams TE, New views on periodontal microbiota in special patient categories. J Clin Periodontol 1991;18:411-20.

2. Tanner A, Bouldin HD, Maiden MF. Newly delineated periodontal pathogens with special reference to selenomonas species. Infection 1989;17:182-87.

3. Wolff L, Dahlen G, Aeppli D. Bacteria as risk markers for periodontitis. J Periodontol 1994;65:498-510.

4. Gibbs RA. DNA amplification by the polymerase chain reaction. Anal Chem 1990;62:1202-14.

5. Holt SC, Progulske A. General microbiology, metabolism and genetics. In: Neuman MG, Nisengard R, (Eds). Oral microbiology and immunology. Philadelphia: Saunders 1988.

6. Saiki R, Gelfand DH, Stoffel S, et al. Primer directed enzymatic amplification of DNA with thermostable DNA polymerase. Science 1988;239:487.

7. Dawson MT, Powell R, Gannon F. Gene technology. Oxford: BIOS Scientific Publishers 1996.

8. Lewin B. Genes. New York: Oxford University Press 1993.

9. Jankowski JA, Polak JM. Clinical gene analysis and manipulation. New York: Cambridge University Press 1996.

10. Shibata DK. The polymerase chain reaction and the molecular genetic analysis of tissue biopsies. In: Herrington CS, McGee JO, (Eds). Diagnostic Oxford: Oxford University Press 1992.

11. Doungudomdacha S, Rawlison A, Douglas WI. Enumeration of Porphyromonas gingivalis, Prevotella intermedia and Actinobacillus actinomycetemcomitans in subgingival plaque samples by a quantitative-competitive PCR method. J Med Microbiol 2000;49(10):861-74.

12. Riggio MP, Lennon A. Rapid identification of Actinobacillus actinomycetemcomitans, Haemophilus aphrophilus, and Haemophilus paraphrophilus by restriction enzyme analysis of PCR-amplified 16S rRNA genes. J Clin Microbiol 1997; 35(6):1630-32.

13. Cortelli SC, Jorge AOC, Querido SMR, Cortelli JR. PCR e cultura na detecção subgengival de Actinobacillus actinomycetemcomitans: Estudo comparativo. Cien Odontol Bras 2003;6(2):58-64.

14. de Lillo A, Booth V, Kyriacou L, Weightman AJ, Wade WG. Culture independent identification of periodontitis associated Porphyromonas and Tannerella populations by targeted molecular analysis. J Clin Microbiol 2004;42:5523-27.

15. Leys EJ, Lyons SR, Moeschberger ML, Rumpf RW, Griffen AL. Association of Bacteroides forsythus and a novel Bacteroides phylotype with periodontitis. J Clin Microbiol 2002;40:821-25.

16. Sanz M, Lau L, Herrera D, Morillo JM, Silva A. Methods of detection of Actinobacillus actinomycetemcomitans, Porphyromonas gingivalis and Tannerella forsythensis in periodontal microbiology, with special emphasis on advanced molecular techniques: A review. J Clin Periodontol 2004;31:1034-47.

17. Tanner AC, Paster BJ, Lu SC, Kanasi E, Kent R Jr, Van Dyke $\mathrm{T}$, Sonis ST. Subgingival and tongue microbiota during early periodontitis. J Dent Res 2006;85:318-23.

18. Shelburne CE, Gleason RM, Germaine GR, Wolff LF, Mullally $\mathrm{BH}$, Coulter WA, et al. Quantitative reverse transcription polymerase chain reaction analysis of Porphyromonas gingivalis gene expression in vivo. J Microbiol Meth 2002 Apr;49(2): 147-56.

19. Mättö J, Saarela M, Alaluusua S, Oja V, Jousimies-Somer H, Asikainen S. Detection of Porphyromonas gingivalis from saliva by PCR by using a simple sample-processing method. J Clin Microbiol 1998 Jan;36(1):157-60.

20. Sakamoto M, Takeuchi Y, Umeda M, Ishikawa I, Benno Y, Nakase T. Detection of Treponema socranskii associated with human periodontitis by PCR. Microbiol Immunol 1999;43(5):485-90.

21. Mullally BH, Dace B, Shelburne CE, Wolff LF, Coulter WA. Prevalence of periodontal pathogens in localized and generalized forms of early-onset periodontitis. J Periodont Res 2000;35(4):232-41.

22. Tran SD, Rudney JD. Improved multiplex PCR using conserved and species-specific 16S rRNA gene primer for simultaneous detection. J Clin Microbiol 1999;37(11):3504-08.

23. Okada M, Hayashi F, Nagasaka N. Detection of Actinobacillus actinomycetemcomitans and Porphyromonas gingivalis in dental plaque samples from children 2 to 12 years of age. J Clin Periodontol 2000 Oct; 27(10):763-68.

24. Hayashi F, Okada M, Zhong X, Miura K. PCR detection of Capnocytophaga species in dental plaque samples from children aged 2 to 12 years. Microbiol Immunol 2001;45(1):17-22.

25. Okada M, Hayashi F, Nagasaka N. PCR detection of 5 putative periodontal pathogens in dental plaque samples from children 2 to 12 years of age. J Clin Periodontol 2001 Jun;28(6):576-82.

26. Takeuchi Y, Makoto U, Sakamoto M, Benno Y, Huang Y, Ishikawa I. Treponema socranskii, Treponema denticola, and Porphyromonas gingivalis are associated with severity of periodontal tissue destruction. J Periodontol 2001 Oct; 72(10):1354-63.

27. Kimura S, Ooshima T, Takiguchi M, Sasaki Y, Amano A, Morisaki I, et al. Periodontopathic bacterial infection in childhood. J Periodontol 2002 Jan;73(1):20-26.

28. Lyons SR, Griffen AL, Leys EJ. Quantitative real-time PCR for Porphyromonas gingivalis and total bacteria. J Clin Microbiol 2000 June;38(6):2362-65.

29. Sakamoto M, Takeuchi Y, Umeda M, Ishikawa I, Benno Y. Rapid detection and quantification of five periodontopathic bacteria by real-time PCR. Microbiol Immunol 2001;45(1): 39-44.

30. Kumar PS, Griffen AL, Barton JA, Paster BJ, Moeschberger ML, Leys EJ. New bacterial species associated with chronic periodontitis. J Dent Res 2003;82(5):338-44.

31. Eick S, Pfister W. Comparison of microbial cultivation and a commercial PCR based method for detection of periodontopathogenic species in subgingival plaque samples. J Clin Periodontol 2002;29:638-44.

32. Squeri R, La Fauci V, Cannavo G, LO Giudice G, Sindoni L. Identification of the microorganisms responsible for periodontopathy by multiplex RT-PCR. J Prev Med Hyg 2006;47:142-45.

33. Paster BJ, Dewhirst FE. Molecular microbial diagnosis. Periodontology 2000,2009;51:38-44.

34. Parra B, Slots J. Detection of human viruses in periodontal pockets using polymerase chain reaction. Oral Microbiol Immunol 1996 Oct;11(5):289-93.

35. Garlet GP, Martins Junior W, Ferreira BR, Milanezi CM, Silva JS. Patterns of chemokines and chemokine receptors expression in different forms of human periodontal disease. J Periodont Res 2003;38:210-17.

36. Sahoo B. Polymerase Chain Reaction-Part I: Principle, Components, Procedure and Stages of PCR. Available from: http://pharmaxchange.info/press/2011/07/polymerase-chainreaction. 
37. Valones MAA, Guimarães RL, Brandão LAC, de Souza PRE, Carvalho ADAT, Crovela S. Principles and applications of polymerase chain reaction in medical diagnostic fields: A review. Braz J Microbiol 2009;40:1-11.

38. Kim Y, Flynn TR, Donoff RB, Wong DTW, Todd R. The gene: The polymerase chain reaction and its clinical application. J Oral Maxillofac Surg 2002;60:808-15.

\section{ABOUT THE AUTHORS}

\section{Suvarna H Patil (Corresponding Author)}

Professor and Head, Department of Periodontics, KLE VK Institute of Dental Sciences, Belgaum, Karnataka, India, e-mail: drsuvarnapatil@ yahoo.co.in

\section{Kishore G Bhat}

Research Officer, Heart Foundation, KLES Dr. Prabhakar Kore Hospital and Medical Research Centre, Belgaum, Karnataka, India

\section{Paresh S Lotlekar}

Postgraduate Student, Department of Periodontics, KLE VK Institute of Dental Sciences, Belgaum, Karnataka, India

\section{Laxmi V Hombal}

Postgraduate Student, Department of Periodontics, KLE VK Institute of Dental Sciences, Belgaum, Karnataka, India 